\title{
CALL-TO-ACTION: FACEBOOK NA EDUCAÇÃO, BREVE RELATO
}

\author{
CURITIBA/PR MAIO/2018
}

\begin{abstract}
Alvaro Martins Fernandes Júnior - UNINTER - alvarojunior777@gmail.com
Siderly do Carmo Dahle de Almeida - UNINTER - siderly.c@gmail.com

Antoine Youssef Kamel - UNINTER - aNTOINE.K@uninter.com

Andrea Benetti de Oliveira - UNINTER - ANDREA.O@UNINTER.COM
\end{abstract}

Tipo: Relato de Experiência Inovadora (EI)

Categoria: Métodos e Tecnologias

Setor Educacional: EDUCAÇÃO SUPERIOR

\begin{abstract}
RESUMO
O trabalho explicita uma ação educacional utilizando as redes sociais, mais especificamente a pagina no Facebook de dois cursos superiores, o tecnólogo em Gestão de Serviços Jurídicos e Notarias e o Bacharelado em Ciência Politica. A ação consistiu na postagem de uma noticia, seguida de um Call-to-action, na página do curso tecnólogo, em seguida o compartilhamento no curso bacharelado, onde a ação esperada realmente aconteceu. Embora os números não sejam os maiores motivadores e o grande catalisador do sucesso na ação, as postagens realizadas pelos seguidores foram de grata surpresa. Antes da exposição da experiência são explorados alguns números de suas grandes pesquisas brasileiras sobre o uso e acesso a internet no Brasil, isso aconteceu no intuito de justificar a falta de interação dos alunos e também para descontruir alguns sensos comuns que citamos na introdução do trabalho.
\end{abstract}

Palavras-chave: Call-to-action, facebook, Ensino Superior

\section{AGRADECIMENTOS}

AGRADECIMENTO AO CENTRO UNIVERSITÁRIO INTERNACIONAL UNINTER POR NOS PERMITIR PROPICIAR MOMENTOS DE APRENDIZAGEM AOS NOSSOS ALUNOS. 


\section{INTRODUÇÃO}

Sempre que uma tecnologia fica disponível para o consumo da sociedade como um todo, se começa a questionar as potencialidades do seu uso na educação. E ainda mais, como ela pode "revolucionar" a educação fazendo com que os alunos "realmente se interessem" por estudar dado que o professor passa a "considerar a realidade do aluno" então, isso vai garantir maiores aprendizagens por parte dele.

As aspas, claro, são ironia, em referência ao senso comum que se estabelece dessa relação educação e tecnologias. Onde todo discurso é seguido de: "o professor TEM que usar tecnologia na sala de aula", ou "todo mundo TEM celular, o professor tem que usar ele na sala de aula", e por fim, mas não a última, "todo mundo TEM acesso a internet, ela é o caminho".

O trabalho é um relato de caso que demonstra pequenos avanços na área tecnologias na educação, mais especificamente fazendo o uso de redes sociais (uma frase com ela também poderia estar no parágrafo acima), mas também desmistifica os sensos comuns dos parágrafos acima.

Portanto o que será compartilhado neste trabalho são alguns dados referentes ao acesso as tecnologias pelos pela população brasileira, em seguida, compartilha-se uma experiência considerada exitosa fazendo o uso de redes sócias como uma metaatividade na educação a distância.

Embora, possa parecer não haver relação entre o compartilhamento de dados sobre acesso aos meios de comunicação pelos alunos e o êxito da experiencia na rede social, nas considerações finais é realizado a costura dos dados, justificando assim, a relação proposta.

\section{O ACESSO A INTERNET NO BRASIL E O GRAU DE CONFIANÇA NELA}

A Pesquisa Brasileira de Mídia (PMB) 2016 é desenvolvida pela Secretaria Especial de Comunicação Social da Presidência da República, e foi realizada com mais de 15.000 brasileiros de todas as Unidades Federativas do país demonstrando um resultado que já rechaça o senso comum do acesso a informação fazendo o uso da internet, a pesquisa que possui nível de confiança de $95 \%$ demonstra dados interessantes

A PBM do ano de 2016 verifica que a rede mundial de computadores se cristaliza como segunda opção dos brasileiros na busca de informação, atrás somente da televisão. Quase a metade dos brasileiros (49\%) declarou usar a web para obter notícias (primeira e segunda menções), percentual abaixo da TV (89\%), mas bem acima do rádio (30\%), dos jornais (12\%) e das revistas (1\%). (BRASIL, 2016, p. 11) 
Essa questão de confiança no que se vê na internet apresenta mais pontos interessantes, onde $45 \%$ dos analfabetos afirmam nunca confiar em noticias que circulam em sites, enquanto $61 \%$ de pessoas com superior incompleto (prováveis alunos do ensino superior) afirmam confiar poucas vezes no noticiário da rede mundial de computadores, e apenas $12 \%$ destes nunca confiam. $O$ dado contrário também é de relevância, $4 \%$ dos analfabetos e $21 \%$ dos que possuem superior incompleto confiam muitas vezes, e $9 \%$ dos analfabetos e $5 \%$ do outro grupo confiam sempre. (BRASIL, 2016)

Quando o assunto são as redes sociais encontramos um grau de desconfiança bem alto também, onde $13 \%$ dos analfabetos confiam sempre, $21 \%$ nunca confiam e $46 \%$ confiam poucas vezes. Com relação aos que possuem superior incompleto encontramos que apenas $3 \%$ confiam sempre, seguidos de $23 \%$ que nunca confiam e $62 \%$ que confiam poucas vezes.

Isso é ponto relevante, afinal segundo estudo do Grupo de Pesquisa em Políticas Públicas para o Acesso à Informação (Gpopai) da Universidade de São Paulo (USP), 12 milhões de brasileiros difundem "fake News" politicas. (MARTINS, 2017).

A internet, então, se estabelece sobre um paradoxo, é fonte de informação, mas não de confiança, afinal como foi visto a televisão ainda é a maior fonte de busca de informação, ou seja, e também quem "valida" as informações do mundo virtual, portanto, se a internet não se consolida como um meio que transmite confiança, ela deve ser passível de questionamento e uso reflexivo quanto ao seu uso educacional.

Então, embora haja um consumo frequente de produtos da internet é nos meios convencionais que a população afirma buscar a validação do que costumam ver na internet, "os internautas se conectam com forte intensidade, mas ainda buscam nos meios tradicionais a validação daquilo que veem." (BRASIL, 2016, p.08)

A internet como um todo provê o acesso a informação, enquanto a educação busca pelo conhecimento.

Outra pesquisa, a TIC Domicilios 2016 que entrevistou mais de 23 mil brasileiros aponta que $97 \%$ dos lares brasileiros possuem TV, seguido por 93\% que possuem telefone celular, e bem atrás, o rádio presente em $66 \%$ dos domicílios. Porém, celular não é sinônimo de acesso à internet, dado que $46 \%$ dos municípios brasileiros não possuem acesso a ela, seja por banda móvel ou fixa. (CETIC, 2017) 
Entre as atividades on-line, as mais mencionadas continuam sendo o uso da Internet para envio de mensagens instantâneas (89\%) e uso de redes sociais (78\%) - proporções que se mantiveram estáveis em relação à edição anterior da pesquisa. (CETIC, 2017, p.121)

Outro grande problema é uso que as pessoas fazem com o seu acesso a internet, dado que na pesquisa não foi apontada a opção de que usa a internet para estudar, o mais próximo disso foi a opção "leu jornais, revistas ou notícias on-line" que teve 50\% das intenções dos respondentes. E isso se aproxima da afirmação da PBM 2016 que quase metade $(49 \%)$ de seus entrevistados mencionam o fato de acessar a rede mundial de computadores como meio para se informar mais sobre o que acontece no Brasil.

O que é preocupante é que os entrevistados, de ambas as pesquisas, não entendam esse ato como educativo, e pior, não citam que usam a internet para atividades educativas. Mesmo com o advento da educação a distância e o aumento da oferta de cursos na modalidade, a opção "uso a internet para estudar" já deveria figurar entre assertivas de pesquisas sobre usos da internet.

Então, para tentar tornar o ato educativo mais intencional e considerando os índices de acesso as redes sociais do brasileiro é que se cita a experiência no capítulo seguinte.

\section{CALL-TO-ACTION, DANDO VOZ AOS ALUNOS}

Call-to-action, CTA, (em português, Chamada para ação) é a principal forma de convidar o seguidor de uma pagina a realizar uma ação nela. A mera postagem de um conteúdo não gera interações e engajamento dos seguidores, costuma apenas gerar reações(curtir, amei, haha, uau e triste). Geralmente o CTA leva o usuário a clicar em um link e ser levado para uma página externa a rede social e esta pode conter um produto a venda ou um formulário a ser preenchido.

Aa experiência relatada aconteceu no Facebook, e constitui na postagem de uma noticia sobre a presença da inteligência artificial nas eleições japonesas[1] seguida de um CTA, ou seja, foi postado um trecho da notícia, seu link e ao final foi realizada uma questão sobre a opinião dos seguidores sobre o tema. A matéria foi postada na página do Curso Superior de Gestão em Serviços Jurídicos e Notariais (tecnólogo) de uma IES privada e em seguida compartilhada na página do curso de Ciência Política (bacharelado) da mesma IES.

A página do curso de Gestão em Serviços Jurídicos e Notariais possui 5118 seguidores e com a publicação citada teve 16 compartilhamentos, 1 comentário e alcançou 1855 pessoas, ou seja, a mensagem foi exposta à todas essas pessoas. Porém, a ação a ser 
relatada aqui aconteceu na página de Ciência Política, que possui 3625 seguidores, e que contou com 7 compartilhamentos e 6 comentários.

Embora os números sejam baixos, o sucesso vem da análise da qualidade dos comentários expostos na página. A rede social contabiliza apenas 6 comentários pois desconsidera os comentários dentro dos comentários, e o administrador da página respondeu a todos sempre deixando espaço para que o seguidor fizesse mais alguma interação.

Como a reportagem era sobre a presença de inteligência artificial nas eleições japonesas foi questionado se um robô pode ser um gestor político melhor que o ser humano. O resultado foi a apresentação de várias respostas de alto nível, como a resposta que se segue

\begin{abstract}
"É de se pensar. A inteligência artificial foi programada por um ser humano, passível de ser corrompido, que pode programar variáveis para que ela não execute seu mandato de forma legal e ética. Se pensarmos que vários perfis já estão sendo utilizados nas redes sociais por inteligência artificial para "controlar" as opiniões e as notícias, interferindo em eleições como foi nos Estados Unidos. À quem interessa este tipo de manipulação? Onde há democracia ela está sendo desenvolvida como deveria? A meu ver no Brasil não está. Tem vários seres humanos "robôs" repetitivos de ideias disseminadas, sem conseguirem fazer um juízo crítico de situações, como as políticas, somente repetindo o que uma ou outra corrente diz. Mas, em se tratando de Japão, é outro nível, né! Talvez lá dê certo!"
\end{abstract}

Essa postagem teve retorno do administrador da página com a seguinte resposta

"Excelente contribuição Adriana. Concordo que os países devem estar preparados eticamente para receber esse novo mecanismo. Vamos ver o que acontece, as vezes pode ser apenas mais uma ação de marketing de alguma grande empresa, vamos esperar!!!"

E por fim o seguidor terminou,

“Obrigada Ciência Política Uninter! É isso aí, talvez só seja marketing, vamos aguardar. Estou amando o curso!"

Um outro seguidor foi mais a fundo no debate com o moderador da página

"Será que num futuro distante, essa IA/robô teria capacidade analítica para fazer julgamentos e atuar no judiciário? Já que é impossível um juiz ser plenamente imparcial, por questões naturais da nossa espécie - ser parcial em qualquer juízo de valor."

\title{
E teve como resposta
}

"Olha Felype, é bem complicado. E a resposta você mesmo já deu no seu comentário: o ser humano é imparcial por natureza, e o robô é feito por seres humanos, então?! Aliás, tem como ser imparcial? todo mundo tem um lado, 
ou não?"

Que voltou a interagir

"De fato os robôs são criações humanas, mas não quer dizer que o mesmo se tornará a sombra dos seus criadores - já que os mesmos podem aprender sozinhos e criar uma nova percepção da realidade. Acredito que a imparcialidade seja possível, e a IA pode ajudar na compreensão disso. Contudo, apesar de alguns avanços, acredito que estamos engatinhando (ainda), todavia, estamos livres para debater acerca desse assunto tão formidável, e imaginar um futuro completamente diferente, com outras problemáticas e soluções."

A ultima postagem de um seguidor, e que ainda não foi respondida é a que segue,

\begin{abstract}
"O IA/Robô pode até contribuir, sendo uma ferramenta para ajudar na tomada de decisões na gestão pública, mas a palavra final tem que ser sempre dos líderes humanos, não sou a favor de entregar o poder executivo à uma máquina, se não daqui a pouco vamos viver uma Ditadura robótica, onde as decisões de um robô sobrepõem à vontade humana, não acredito em uma política desse nível, o homem ainda com a existência de tecnologia avançada deve estar sempre acima das suas criações. A evolução política e social do homem deve ser aprimorada e executada pelo próprio homem, o robô deve ser uma "extensão" do homem no poder e não um substituto! E os robôs devem respeitar a democracia e passarem pelos mesmos dispositivos eleitorais que os humanos, ou seja, se um robô quiser tomar uma decisão isolada sobre o Estado eu não concordaria, ainda que defensores de um Estado totalitário digam que: "o robô é mais inteligente que nós, ele sabe o que está fazendo, nós somos humanos falhos e devemos nos submeter à inteligência artificial perfeita do presidente, prefeito, juiz robô..." nossa que loucura pareceria coisa de filme, eu particularmente não aceitaria a sua decisão e a população deveria ter o direito de trocar os robôs. Mas pela lógica, o robô deve ser perfeito para corrigir a falha humana, não precisaria ser substituído. Mas será? Não acredito! Fiquemos com os homens, eles têm sentimentos e são substituíveis, ou pelo voto ou pela morte natural. Imagina... robô não morre, ficaria no poder para sempre! Rss"
\end{abstract}

Conforme já adiantado, os números não são o que mais importam na experiência relatada, mas sim a qualidade dos comentários dos seguidores da página, e a isso se deve a experiência exitosa.As tecnologias não são, jamais, substitutos do conteúdo e da interação proporcionada por meio delas. Como aponta m Mahlmeister e Mattar (2016, p. 5), os docentes é que devem ter "a intenção de despertar nesse aluno o desejo de se entregar cognitivamente ao conteúdo e ao método proposto", "pois sem isso de nada adiantarão a tecnologia, as redes sociais ou o quadro-negro". E esse intuito é efetivado nas páginas do Facebook dos cursos mencionados por meio de interesse ativo e despertamento à ação. As hipóteses que se levantam do número de interações não ser maior se relacionam com o apresentado no capitulo 1, onde não é toda a população que possui acesso a internet, e que embora as pessoas acessem as redes sociais, o fazem para outras ações, não para atividades educativas. Por fim, o desinteresse dos seguidores pelo assunto também deve ser considerado nesta análise, e é mais uma hipótese para não haver maior número de interações.

No estudo de caso de Ferreira Lima et al (2016), dois elementos fortes, dentre os ali citados, foram constatados em comparação à presente aplicação: a motivação e a 
sociabilidade. Quanto à este, os alunos interagem entre si neste ambiente de uma maneira informal e aberta que não é de todo possível no ambiente estritamente acadêmico, concebido pelo ambiente virtual de aprendizagem. $E$, quanto àquele elemento, foi percebido que a presença do professor é necessária, e, ao contrário, a ausência do professor por alguns dias faz com que os alunos percam a motivação de participar. Essas constatações fazem com que o trabalho de gestão da página do curso seja feita com maior presença do docente e maior incentivo à participação.

\section{CONSIDERAÇOES FINAIS}

Os números são um alento aos professores que ainda não aderem as "tendências na educação", dado que somando o número de seguidores das duas páginas envolvidas era de se esperar uma maior quantidade de comentários (mesmo que mais curtos), e reações (curtir, haha, amei, triste e uau), e porque não compartilhamentos. Ou seja, embora não seja novidade, e o senso comum insista em dizer o contrário, a tecnologia não é a solução dos problemas na educação, porém, ela está ai para contribuir.

A experiência é exitosa do ponto de vista da qualidade dos comentários, demonstrando que o ensino a distância é formada por alunos competentes e críticos da realidade social. É mais uma pesquisa, dentre poucas, que abordam as redes sociais na educação considerando ela como mais uma alternativa, mas não a salvadora da Pátria.

Se entre os usuários de internet do Brasil, $78 \%$ das pessoas a utiliza para acessar as redes sociais era de se esperar maior interação com a postagem. Porém, conforme elencado no capítulo anterior, a falta de interesse dos alunos pelo assunto também deve ser considerado.

\section{REFERENCIAS}

FERREIRA LIMA, Danilo Lopes et al. Utilização da rede social facebook como ferramenta de interatividade em disciplina a distância. In: Anais do 22을 Congresso Internacional ABED de Educação a Distância, 2016. Disponível em: <http://www.abed.org.br/congresso2016/trabalhos/108.pdf>. Acesso em: 22 maio 2018.

BRASIL, Presidência da República. Secretaria Especial de Comunicação Social. Pesquisa brasileira de mídia 2016 : hábitos de consumo de mídia pela população brasileira. - Brasília : Secom, 2016.

CETIC. Pesquisa sobre o uso das tecnologias de informação e comunicação nos 
domicílios brasileiros : TIC domicílios / Núcleo de Informação e Coordenação do Ponto BR [editor] -- São Paulo -- Comitê Gestor da Internet no Brasil, 2017.

MARTINS, Alexandra. Na web, 12 milhões difundem fake news políticas. Disponível em: http://politica.estadao.com.br/noticias/geral,na-web-12-milhoes-difundem-fake-newspoliticas,70002004235 Acesso em: 19 mai. 2018.

MAHLMEISTER, Leticia; MATTAR, João. Facebook e ambientes virtuais de aprendizagem: análise da interação na educação a distância. In: Anais do 220 Congresso Internacional ABED de Educação a Distância, 2016. Disponível em: <http://www.abed.org.br/congresso2016/trabalhos/29.pdf>. Acesso em: 22 maio 2018.

[1] https://www.ab2l.org.br/inteligencia-artificial-e-candidata-eleicoes-municipais/ 